\title{
MATHEMATICAL LOGIC
}

\author{
Br \\ Willard Van Orman Quine
}

REVISED EDITION

HARVARD UNIVERSITY PRESS

Cambridge, Massachusetts

London, England 
COPYRIGHT, 1940, 1951, (C) 1979, 1981, BY

Willard Van Orman Quine

This book has been digitally reprinted. The content remains identical to that of previous printings.

LIBRARY OF CONGRESS CATALOG CARD NUMBER 80-85313

ISBN 0-674-55450-7 (CLOTH)

ISBN $0-674-5545$ I -5 (PAPER) 